\title{
Obstrüktif Uyku Apne Sendromu Olan Hastalarda Klinik ve Demografik Verilerinin Değerlendirilmesi
}

\author{
Evaluation of Clinical and Demographic Data in Patients with Obstructive \\ Sleep Apnea Syndrome
}

\author{
Ahmet Yıldırım ${ }^{1}$, Aysel Tekeşin ${ }^{2}$ \\ ${ }^{1}$ Şanlıurfa Eğitim ve Araştırma Hastanesi, Nöroloji Kliniği, Şanlıurfa, Türkiye \\ ${ }^{2}$ Sağllk Bilimleri Üniversitesi, İstanbul Ĕ̆itim ve Araştırma Hastanesi, Nöroloji Kliniği, İstanbul, Türkiye

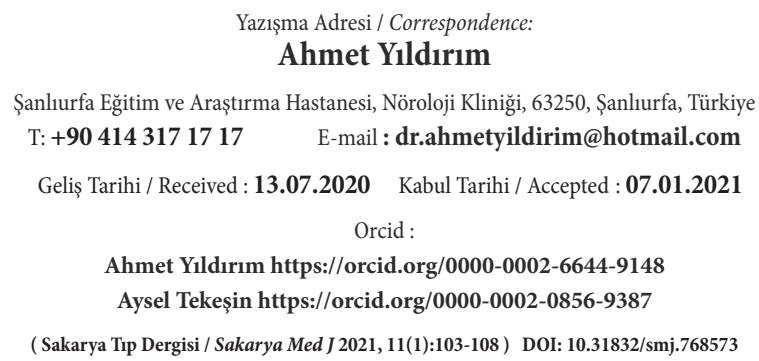

$\ddot{O} z$

Amaç Çalıșmanın amacı uykuda horlama ve/veya solunum durması şikayetleriyle başvuran hastalarda obstrüktif uyku apne sendromu (OUAS) varlığının değerlendirilmesi ve OUAS'lı hastaların demografik verilerini ve eşlik eden kronik hastalık birlikteliğini araştırmaktır.

Gereçve Bu çalışmada Ocak 2017- Haziran 2018 tarihleri arasında, uykuda horlama ve/veya solunum durması şikayetleriyle İstanbul Eğitim ve Araştırma Hastanesi uyku

Yöntem laboratuvarına yönlendirilen hastalar incelendi. Çalışmaya 385 hasta dahil edildi. Hastaların anamnezleri alınarak horlama ve/veya solunum durması șikayetlerinin yanı sıra kronik rahatsızlıklarının olup olmadığı sorgulanmıs, alıskanlıkları ve demografik verileri kaydedilmiștir. Hastalarda OUAS varlığının tespiti için 1 gece süreyle polisomnografi (PSG) testi yapılmış ve Apne Hipopne İndeksine (AHI) göre hastalar gruplandırılmıștır. Test sonucunda AHİ $\geq 5$ olması OUAS olarak kabul edilmiştir. AHİ 5-14,9 arası hafif, 15-29,9 arası orta, 30 ve üzeri ağır olarak gruplandırılmıștır. Polisomnografi test sonucunda, AHİ 5'in altında olan ve horlaması olan hastalar basit horlama olarak gruplandırılmıștır. Hastaların ayrıca periyodik bacak hareket indeksi (PBHİ) değerlendirilmiștir.

Bulgular Polisomnografi test sonuçlarına göre hastaların 100'ü basit horlama (\%26), 103'ü (\%26,7) hafif derecede OUAS, 84'ü $(\% 21,8)$ orta derecede OUAS ve 98'i $(\% 25,4)$ ağı derecede OUAS olarak değerlendirilmiștir. OUAS hastalarında erkek cinsiyetin hakim olduğu, hipertansiyonun daha sık görüldüğü, daha yüksek VKİye sahip oldukları ve ileri yaşın da OUAS için bir risk faktörü olduğu saptanmıştır.

Sonuç OUAS için risk faktörlerinin bilinmesi, OUAS komplikasyonlarına karşı erken önlem alınabilmesi adına yol gösterici olacaktır

Anahtar Polisomnografi; horlama; obstrüktif uyku apne sendromu

Kelimele

Abstract

Objective The aim of the study is to evaluate the presence of Obstructive Sleep Apnea Syndrome

(OSAS) in patients presenting with snoring and/or apnea complaints and to investigate demographic data of patients with OSAS and the comorbid chronic disease.

Materials In this study, patients who were referred to Istanbul Training and Research Hospital sleep laboratory between January 2017 and June 2018 with complaints of snoring and apnea during sleep and methods were examined. 385 patients were included in the study.

The anamnesis of the patients were taken, and the presence of chronic diseases as well as the complaints of snoring and/or apnea were questioned, and their habits and demographic data were recorded. One night polysomnography test was performed to determine the presence of OSAS in patients and the patients were grouped according to Apnea Hypopnea Index (AHI). Having $A H I \geq 5$ was accepted as OSAS, AHI was included between 5-14.9 mild, moderate between 15.0-29.9, severe as 30 and higher. As a result of polysomnography test, patients with AHI below 5 and snoring were grouped as simple snoring. Periodic leg movement index (PLMI) of the patients were also evaluated.

Results According to the polysomnography test results, 100 were evaluated as simple snoring (26\%), 103 (26.7\%) were mild OSAS, 84 (\%21.8) were moderate OSAS, and 98 (25.4\%) were severe OSAS. It was determined that male gender is dominant in OSAS patients, hypertension is more common, they have higher BMI and advanced age is a risk factor for OSAS.

Conclusion Determination of risk factors for OSAS, it will be a guide for taking early precautions against OSAS complications.

Keywords Polysomnography; snoring; obstructive sleep apnea syndrome 


\section{GIIRIŞ}

Obstrüktif uyku apne sendromu (OUAS), uyku esnasında tekrarlayan üst solunum yolu obstruksiyonu epizotları ve beraberinde arteryel oksijen saturasyonunda azalma ile tanımlanan bir sendromdur. Bu durum basit horlamaya neden olan hava yolunun kısmi obstrüksiyonundan apne oluşumuna neden olan hava yolunun tam obstrüksiyonuna kadar değişebilir. Uyku esnasında üst hava yolu kapanmasının ana sebebi hava yolunu açık kalmasını sağlayan ve kollapsına neden olan güçlerin dengesinin bozulmasıdır. ${ }^{1}$ OUAS’ın tipik bulguları, uykuda tekrarlayan üst solunum yolu tıkanmasına bağlı horlama, tanıklı apne ve gündüz aşırı uyku halidir. OUAS tanılı hastalarda sık uyanma ve sonuçta bölünmüş uyku nedeniyle gün içi yorgunluk, baş ağrısı, dikkat eksikliği, motorlu taşıt kazaları, cinsel isteksizlik ve iş performansında azalma görülmektedir. Sosyal ve nöropsikolojik sonuçlarının yanı sıra kardiyovasküler sonuçlarıyla da ciddi morbidite ve mortalite nedenidir. ${ }^{2}$ OUAS tanısı için altın standart polisomnografidir (PSG) ${ }^{3}$. İleri yaş, VKİ’nin yüksek olması (obezite), alkol ve sigara kullanımı, erkek cinsiyet OUAS için risk faktörleridir. ${ }^{4}$ Çalışmanın amacı uykuda horlama ve/veya solunum durması şikayetleriyle başvuran hastalarda obstrüktif uyku apnesi (OUAS) varlığının değerlendirilmesi ve OUAS’ı olan hastaların demografik verilerini ve eşlik eden kronik hastalık birlikteliğini araştırmaktır.

\section{GEREÇ ve YÖNTEMLER}

Ocak 2017- Haziran 2018 tarihleri arasında polikliniğimize gece uykuda horlama, gündüz aşırı uyku hali ve tanıklı apne belirtilerinden bir ya da daha fazlası ile başvuran 392 hasta incelendi. Çalışmaya katılmaya engel teşkil eden nörolojik hastalığı olan 4, mental retardasyonu olan 2 ve son 6 ayda madde kullanım öyküsü olan 1 hasta olmak üzere toplam 7 hasta araştırma dışı bırakılarak toplam 385 hasta çalışmaya alındı. Hastaların anamnezleri alınarak horlama ve/veya uykuda solunum bozukluğu şikayetlerinin yanı sıra başka bir kronik rahatsızlıklarının olup olmadığı kalp yetmezliği, kalp ritim bozukluğu, kalp krizi hikayesi, şeker hastalığı, kronik obstrüktif akciğer hastalığı, hipertiroidi. hipotiroidi, hipertansiyon öyküsü sorgulandı ve bunların dışında rahatsızlıkları olanların belirtmesi istendi. Hastaların alışkanlıkları, demografik verileri ve VKİleri kaydedildi. Hastalarda OUAS varlığının tespiti için 1 gece süreyle PSG testi yapıldı ve Apne Hipopne İndeksine (AHI) göre hastalar gruplandırıldı. AHI $\geq 5$ olması OUAS olarak kabul edildi. PSG test sonucunda $A H \dot{I}<5$ ve horlaması olan hastalar, basit horlama olarak grupland1rildi.

1) Apne-hipopne indeksi (AHİ) 5-14,9 olan; hafif OUAS

2) AHİ: 15-29,9 olan; orta düzey OUAS

3) AHİ $\geq 30$ olan; ağır OUAS kabul edildi.

4- $\mathrm{AHI}<5$ ve horlaması olan hastalar, basit horlama olarak gruplandirıldı.

Hastalar PSG testi ile değerlendirildi. PSG'de; elektroensefalografi, elektrookülografi, çene ve bacak elektromiyelografisi, elektrokardiografi, oro-nazal termistor ile hava ak1mı, göğüs ve karın solunum hareketleri, parmak ucu pulse oksimetre ile oksijen saturasyonu, boyuna yerleştirilen trakeal mikrofon ile horlama ve vücut pozisyonu kaydedildi.

Etik kurul onayı Sağlık Bilimleri Üniversitesi İstanbul Eğitim ve Araştırma Hastanesi etik kurulundan 26/10/2018 tarihinde alınmıştır (Karar no:1478).

İstatistiksel verilerin analizinde IBM SPSS forwindows 20 istatistik paket programı kullanıldı. Niteliksel verlerin değerlendirilmesinde Ki-kare ve Fisherexact test, 2 grup arasındaki nicel verilerin karşılaştırılmasında student's t test ve Mann whitney u testleri, OUAS dereceleri arasındaki karşılaştırmalarda ANOVA ve Kruskalwallis testleri kullanıldı. $\mathrm{P}<0,05$ anlamlı kabul edildi.

\section{BULGULAR}

Hastaların 239'u erkek 146'sı kadındı. PSG test sonuçlarında AHİ’ye göre hastaların 100’ü basit horlama (\%26), 285‘i (\%74) OUAS hastası olarak değerlendirilmiştir. 
Çalışmamızda OUAS tanılı nefes alamama şikayetleri ve HT’nin varlığı, basit horlaması olan hastalara göre anlamlı derecede fazlaydı $(\mathrm{p}<0,05)$. DM varlığ 1 ile OUAS arasında ise ile anlamlı bir ilişki saptanmamıştır (Tablo-1).

\begin{tabular}{|c|c|c|c|c|c|c|}
\hline \multicolumn{7}{|c|}{$\begin{array}{l}\text { Tablo 1: Basit horlaması olan ve OUAS’ı olan hastaların de- } \\
\text { mografik verileri, klinik özellikleri ve eşlik eden hastalıkların } \\
\text { karşılaştırılması }\end{array}$} \\
\hline & \multicolumn{2}{|c|}{$\begin{array}{l}\text { OUAS tanılı } \\
\text { hastalar }\end{array}$} & \multicolumn{2}{|c|}{$\begin{array}{c}\text { Basit horlaması } \\
\text { olan hastalar }\end{array}$} & \multirow{2}{*}{$\begin{array}{c}\text { Ki- } \\
\text { kare }\end{array}$} & \multirow{2}{*}{$\mathrm{p}$} \\
\hline & $\mathrm{n}$ & $\%$ & $\mathrm{n}$ & $\%$ & & \\
\hline \multicolumn{7}{|l|}{ Cins } \\
\hline$E$ & 192 & 67,4 & 47 & 47,0 & & \\
\hline $\mathrm{K}$ & 93 & 32,6 & 53 & 53,0 & 13,04 & 0,0001 \\
\hline \multicolumn{7}{|c|}{ Uykuda Nefes Durması } \\
\hline Yok & 35 & 12,3 & 25 & 25,0 & & \\
\hline Var & 250 & 87,7 & 75 & 75,0 & 9,10 & 0,003 \\
\hline \multicolumn{7}{|c|}{ Ek Hastalık } \\
\hline Yok & 253 & 88,8 & 92 & 92,0 & & \\
\hline Var & 32 & 11,2 & 8 & 8,0 & 0,83 & 0,363 \\
\hline \multicolumn{7}{|l|}{$\mathrm{DM}$} \\
\hline Yok & 275 & 96,5 & 96 & 96,0 & & \\
\hline Var & 10 & 3,5 & 4 & 4,0 & 0,05 & 0,821 \\
\hline \multicolumn{7}{|l|}{ HT } \\
\hline Yok & 258 & 90,5 & 97 & 97,0 & & \\
\hline Var & 27 & 9,5 & 3 & 3,0 & 4,31 & 0,038 \\
\hline
\end{tabular}

Çalışmamızda 103 hasta $(\% 26,7)$ hafif derecede OUAS, $84(\% 21,8)$ orta derecede OUAS ve 98 'i $(\% 25,4)$ ağır derecede OUAS olarak değerlendirilmiştir. OUAS derecesine göre risk faktörleri incelendiğinde; orta ve ağır OUAS’ olan hastalarda erkek oranı ve uykuda nefes durması sıklığı hafif olgulara göre anlamlı derecede fazla bulunurken $(\mathrm{p}<0,01)$, OUAS derece grupları arasında ek hastalık, DM ve HT varlığı bakımından istatistiksel olarak anlamlı bir farklılık saptanmadı (Tablo 2).
Tablo 2: OUAS’ı olan hastalarda hastalığın şiddeti ile demografik verilerin, klinik özelliklerin ve eşlik eden hastalıkların karşılaştırılması

\begin{tabular}{|l|c|c|c|c|c|c|c|c|}
\hline & \multicolumn{2}{|c|}{ AĞIR } & \multicolumn{2}{c|}{ ORTA } & \multicolumn{2}{c|}{ HAFİ } & \multirow{2}{*}{$\begin{array}{c}\text { Ki- } \\
\text { kare }\end{array}$} & $\mathrm{p}$ \\
\hline & $\mathrm{n}$ & $\%$ & $\mathrm{n}$ & $\%$ & $\mathrm{n}$ & $\%$ & \\
\hline Cins \\
\hline $\mathrm{E}$ & 75 & 76,5 & 59 & 70,2 & 58 & 56,3 & & \\
\hline $\mathrm{K}$ & 23 & 23,5 & 25 & 29,8 & 45 & 43,7 & 9,78 & 0,007 \\
\hline \multicolumn{7}{|l|}{ Horlama } \\
\hline Yok & 1 & 1,0 & 3 & 3,6 & 8 & 7,8 & & \\
\hline Var & 97 & 99,0 & 81 & 96,4 & 95 & 92,2 & 5,78 & 0,055 \\
\hline
\end{tabular}

Uykuda nefes durması

\begin{tabular}{|l|c|c|c|c|c|c|c|c|}
\hline Yok & 5 & 5,1 & 10 & 11,9 & 20 & 19,4 & & \\
\hline Var & 93 & 94,9 & 74 & 88,1 & 83 & 80,6 & 9,56 & 0,008 \\
\hline
\end{tabular}

\begin{tabular}{|l|c|c|c|c|c|c|c|c|}
\hline \multicolumn{10}{|l|}{ Ek hastalk } \\
\hline Yok & 87 & 88,8 & 72 & 85,7 & 94 & 91,3 & & \\
\hline Var & 11 & 11,2 & 12 & 14,3 & 9 & 8,7 & 1,42 & 0,490 \\
\hline DM \\
\hline Yok & 96 & 98,0 & 78 & 92,9 & 101 & 98,1 & & \\
\hline Var & 2 & 2,0 & 6 & 7,1 & 2 & 1,9 & 4,64 & 0,098 \\
\hline HT & 90104 & & \\
\hline Yok & 90 & 91,8 & 74 & 88,1 & 94 & 91,3 & & \\
\hline Var & 8 & 8,2 & 10 & 11,9 & 9 & 8,7 & 0,84 & 0,657 \\
\hline
\end{tabular}

DM: Diabetes Mellitus, HT: Hipertansiyon, OUAS: Obstrüktif uyku apne sendromu

OUAS derecesi ile PSG verileri arasındaki ilişki incelendiğinde; Orta ve ağır OUAS saptanan hastalarda uyku süresi hafif olgulara göre anlamlı dercede fazla bulunmuştur $(p<0,01)$. Ağır OUAS saptanan hastalarda Rem uyku yüzdesi hafif ve orta OUAS saptanan hastalara göre anlamlı derecede azalmıştır. Ağır OUAS saptanan hastalarda AHI değerleri, orta ve hafif olgulara göre anlamlı derecede fazladır ( $\mathrm{p}<0,001)$. Orta ve hafif olgularda ise PBHİ değerleri ağır olgulara göre anlamlı derecede fazladır $(p<0,01)$. OUAS derece grupları arasında yaş ve VKİ değerleri bakımından istatistiksel olarak anlamlı bir farklılık saptanmadı (Tablo 3). 
Sakarya Tip Dergisi 2021;11(1):103-108

YILDIRIM ve Ark., Obstrüktif Uyku Apne Sendromu Olan Hastalarda Risk Faktörleri

Tablo 3: OUAS’’ olan hastalarda hastalı̆̆ın şiddeti ile demografik ve PSG verilerinin karşılaştııılması

\begin{tabular}{|l|c|c|c|c|c|c|c|}
\hline & \multicolumn{2}{|c|}{ AĞIR } & \multicolumn{2}{c|}{ ORTA } & \multicolumn{2}{c|}{ HAFİF } & SS \\
\hline & ORT & SS & ORT & SS & ORT & P \\
\hline Yaş & 48,97 & 12,26 & 51,90 & 10,87 & 47,64 & 12,35 &, 059 \\
\hline VKİ & 32,76 & 6,53 & 31,09 & 5,67 & 30,50 & 5,16 &, 068 \\
\hline Uyku süresi & 406,69 & 83,98 & 394,74 & 73,90 & 372,95 & 87,46 &, 009 \\
\hline REM uyku \% & 10,88 & 6,58 & 13,12 & 5,5337 & 14,09 & 6,44 &, 002 \\
\hline AHİ & 54,26 & 20,15 & 21,58 & 4,29 & 10,22 & 2,83 &, 0001 \\
\hline PBHİ & 0,13 & 0,87 & 1,97 & 8,38 &, 92 & 6,63 &, 027 \\
\hline
\end{tabular}

VKİ: Vücut kitle indeksi, AHİ: Apne hipopne indeksi, PBHİ: Periyodik bacak hareketleri İndeksi, OUAS: Obstrüktif uyku apne sendromu, ORT: Ortalama, SS: Standart sapma

\section{TARTIŞMA}

Bu çalışmada OUAS tanısı olan hastaların demografik verileri ve komorbid hastalıkları incelendi ve OUAS şiddeti ile korelasyonları araştırıldı. Basit horlama şikayeti olan hastalara göre OUAS hastalarının daha ileri yaşta olduğu, VKİ'nin daha yüksek olduğu, erkek cinsiyet dominansı ve daha yüksek oranda HT varlığı saptandı. Ayrıca OUAS şiddeti arttıkça hastalarda uyku etkinliği yüzdesi ile REM uyku yüzdesinin azaldığı, uyku süresinin ise arttı̆̆ı saptandi.

OUAS toplumda sık görülen, işgücü kaybına ve kronik hastalıkların oluşumuna neden olabilen üst solunum yolu obstrüksiyonu ile giden bir sendromdur. Üst solunum yollarında obstrüksiyon ve kollapsın gelişiminde 3 önemli fizyopatolojik neden vardır. Bunlar; üst solunum yollarının anatomisi, inspirasyon sırasında oluşan negatif basınç ve farengeal hava yolunu dilate eden kaslarda aktivite kaybıdır. ${ }^{5,6}$ Yaş, cinsiyet, obezite, boyun çevresi, sigara, alkol ve sedatif kullanımı ile eşlik eden bazı sistemik hastalıklar ileri sürülen başlıca risk faktörleridir.?

OUAS’ın en sık 40-65 yaş grubunda görüldüğü ve 65 yaşından sonra prevalansının azaldığı kabul edilmektedir. Yaşın OUAS için belirgin bir risk faktörü olduğunu gösteren çalışmalar mevcuttur. ${ }^{8}$ Bizim çalışmamızda olgularımızın

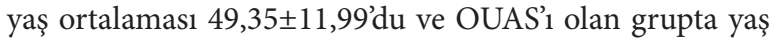
ortalaması, basit horlaması olan gruba göre anlamlı derecede yüksek bulundu. OUAS derecesi ile yaş ortalaması arasında anlamlı ilişki saptanmadı.

Erkek cinsiyeti OUAS için önemli bir risk faktörü olarak kabul edilse de son yıllarda yapılan çalışmalarda, kadınlarda da OUAS’ın azımsanmayacak kadar yüksek oranda görülebildiği ve her yaş grubu için kadın/erkek oranının yaklaşık 1/3 olduğu bildirilmiştir. Nieto ve ark. tarafından 6132 kişi üzerinde yapılan tarama çalışmasında, OUAS tanısı konulan olguların \%37 kadarının kadın olduğu bildirilmiştir. ${ }^{9}$ Bizim çalışmamızda OUAS’lı olguların \%67,4’ü erkek, \%32,6'sı kadındı. Erkek cinsiyet ile OUAS arasında anlamlı bir ilişki saptandı. Ayrıca OUAS şiddeti ile erkek cinsiyet arasında da anlamlı bir ilişki saptandı.

OUAS fizyopatolojisinde obezite önemli bir yer tutmaktadır. ${ }^{10}$ Yapılan çalışmalar obezitenin varlığı nedeniyle; farengeal yağ pedleri, dil, lateralfarengeal duvarlar ve yumuşak damak gibi dokulardaki yağ depolarının artmasi sonucunda üst havayolu enine kesit alanında azalma ve havayolunda kollaps olabilme yatkınlığında artma ile OUAS arasındaki ilişki gösterilmiştir. ${ }^{11-14}$ Obezite derecesini değerlendirmek için en sık kullanılan parametre vücut kitle indeksidir (VKİ). Bizim çalışmamızda VKİ ile OUAS arasında anlamlı ilişki saptandı. Ancak OUAS şiddeti ile VKİ arası anlamlı ilişki saptanmadı.

Normal kişilerde sistemik kan basıncı uyku esnasında \% 20-23 oranında azalır ve uyanma ile birlikte normal günlük olan seviyesine tekrar gelmesine rağmen, şiddetli 
horlama ve OUAS’’ olan hastalarda gün içerisinde ve uyku esnasında sistemik kan basıncında progresif artış olduğu saptanmıştır. ${ }^{15}$ Uykuda apne ve hipopne atakları arterial kan basıncında $30 \mathrm{~mm}$-Hg veya daha fazla artışı da içeren geçici kan basıncı değişikliklerine sebep olur. Renin-anjiyotensin ve vazoaktifpeptidlerdeki değişiklikler ve özellikle kilolu uyku apneli hastalarda görülen insülin rezistans sendromuda hipertansiyon oluşumunu artırabilir. ${ }^{16}$ Bazı çalışmalarda uykuda solunum bozukluğu ve horlama ile şeker hastalığı (DM) gelişimi arasında bir ilişki bulunduğu gösterilmiştir. ${ }^{17,18}$ Bizim çalışmamızda OUAS sendromu ile HT arasında anlamlı ilişki saptanırken DM ile belirgin bir ilişki saptanmamıştır.

OUAS’lı olgularda aşırı uyku hali sık karşılaşılan bir durumdur. Uykularının büyük kısmını yüzeyel uykuda geçiririler ve derin uyku periyodu sıklıkla yetersizdir. Ayrıca apne epizodları ve sık tekrarlayan arousallar ile kalitesiz bir gece uykusu geçirirler. Bu konuda yapılan bir çalışmada hafif dereceli OUAS'lıların \%51,9'u, ağır dereceli OUAS’lıların ise \%88,6's1 sabahları yorgunluk hissi ile uyandıklarını, sırasıyla $\% 61,5$ ve $\% 75$ 'i de yetersiz uyku uyuduklarını bildirmişlerdir ${ }^{17}$. Çalışmamızda da OUAS ile basit horlama arasında uyku etkinliği yüzdesi, uyku süresi ve REM uyku süresi bakımından istatistiksel olarak anlamlı bir farklılık saptanmazken, ağır evre OUAS saptanan hastalarda REM uyku süresinde azalma istatistiksel olarak anlamlı bulunmuştur.

Periyodik bacak hareketleri $(\mathrm{PBH})$ uykuda istemsiz, tekrarlayıcı, stereotipik, kısa süreli, segmental ve sıklıkla alt ekstremitelerin etkilendiği bir tablodur. Al-Alawi ve ark. tarafından yapılan 798 hastanın incelendiği retrospektif bir çalışmada OUAS hastalarının yarısında $\mathrm{PBH}$ varlığ1 saptanmış, PBH varlığı ileri yaş ve kilo artışı ile ilişkili bulunmuştur. Aynı çalışmada, OUAS ile birlikte görülen PBH'nın gün içi uyku hali ve kan basıncı üzerinde etkisi olmadığ 1 bildirilmiştir. ${ }^{20}$ Manconi ve arkadaşlarının yaptığ1 çalışma yüksek AHİ değerlerinin PBH ile ilişkili olduğunu göstermiştir, ${ }^{21}$ ancak bizim çalışmamızda hafif ve orta evre OUAS’lı olgularda PBH varlığı ağır olgulara göre anlamlı derecede fazlayd.

Sonuç olarak çalışmamız, OUAS hastalarında erkek cinsiyetin hakim olduğunu ve hipertansiyonun daha sık görüldügünü göstermiş, bunun yanında daha yüksek VKİye sahip olduklarını ve ileri yaşın da bir risk faktörü olduğunu göstermiştir. Ek olarak OUAS şiddeti arttıkça hastalarda uyku etkinliği yüzdesi ile REM uyku yüzdesinin azaldığı, uyku süresinin ise arttığı saptanmıştır. Bulgularımız, horlama şikayeti ile başvuran hastalarda ileri tetkik için hasta seçimi konusunda yol gösterici olup, OUAS’ın bilinen komplikasyonlarına karşı erken önlem alabilmek adına da önemli veriler sunmaktadır.

\section{Çıkar ilişkisi}

Yazarların herhangi bir çıkar dayalı bir ilişkisi bulunmamaktadir.

Etik kurul onayı Sağlık Bilimleri Üniversitesi İstanbul Eğitim ve Araştırma Hastanesi etik kurulundan 26/10/2018 tarihinde alınmıştır (Karar no:1478). 
Sakarya Tip Dergisi 2021;11(1):103-108

YILDIRIM ve Ark., Obstrüktif Uyku Apne Sendromu Olan Hastalarda Risk Faktörleri

\section{Kaynaklar}

1. Coleman JA. Pathophyology of snoring and sleep apnea: airway dynamics. In Snoring and Obsturictive Sleep Apnea. Ed. Fairbanks D, Mickelson S, Woodson T. Lippincot Williams \&Wilkins .Philadelphia 2003; 2:19-25.

2. Tregear S, Reston J, Schoelles K, Phillips B. Obstructive sleep apnea and risk of motor vehicle crash: systematic review and meta-analysis. J Clin Sleep Med 2009; 5: 573-581

3. Loadsman JA, Hillman DR. Anaesthesia and sleep apnoea. Br J Anaesth 2001; 86: 254-266.

4. Marin JM, Carrizo SJ, Vicente E, Agusti AG. Long-term cardiovascular outcomes in men with obstructive sleep apnoea-hypopnoea with or without treatment with continuous positive airway pressure: an observational study. Lancet 2005;365:1046-53.

5. Köktürk $O$, Köktürk N. Obstrüktif uyku apne sendromu fizyopotolojisi. Tüberküloz ve Toraks 1998; 46: 288-300.

6. Papilla İ, Acıoğlu E. Obstrüktif Uyku Apne Sendromu. Klinik Gelişim 2005; 18: 42-50.

7. Köktürk O. Obstrüktif uyku apne sendromu epidemiyolojisi. Tüberküloz ve Toraks 1998; 46: 193-201

8. McNamara SG, Grunstein RR, Sullivan CE. Obstructive sleep apnea. Thorax 1993; 48: 75463.

9. Nieto FJ, Young TB, Lind BK, et al. Association of sleep-disordered breathing, sleep apnea, and hypertension in large community based study. JAMA 2000; 283: 1829-36.

10. Wittels E, Thompson S. Obstructive sleep apnea and obesity. Otolaryngol Clin North Am 1990; 23; 751-60.

11. Schwab RJ. Upper airway imaging. Clinics in chestmedicine. 1998;19(1):33-54.

12. Stauffer JL, Buick MK, Bixler EO, Sharkey FE, Abt AB, Manders EK, et al. Morphology of the Uvula in Obstructive Sleep Apnea1-3. The American review of respiratory disease. 1989;140:724.
13. Zohar Y, Schwartz A, Sabo R, Gal R, Strauss M, Oksenberg A. Oropharyngeal fatty infltration in obstructive sleep apnea patients: a histologicstudy. Annals of Otology, RhinologyerLaryngology. 1998;107(2):170-4.

14. Nashi N, Kang S, Barkdull GC, Lucas J, Davidson TM. Lingualfat at autopsy. The Laryngoscope. 2007;117(8):1467-73.

15. Fletcher EC, De Behnke RD, Lovoi MS, Gorin AB. Undiagnosed sleep apnea in patients with essential hypertension. Ann Intern Med. 1985;103(2):190-5.

16. Sharabi Y, Dagan Y, Grossman E. Sleep apnea as a risk factor for hypertension. Curr Opin Nephrol Hypertens. 2004;13(3):359-64.

17. Al-Delaimy WK, Manson JE, Willett WC, Stampfer MJ, Hu FB. Snoring as a risk factor for type II diabetes mellitus: a prospective study. Am J Epidemiol. 2002;155(5):387-93.

18. Meslier N, Gagnadoux F, Giraud P, Person C, Ouksel H, Urban T, Racineux JL. Impaired glucose-insulin metabolism in males with obstructive sleep apnea syndrome. EurRespir J. 2003;22(1):156-60.

19. Guilleminault C. Clinical features and evaluation of obstructive sleep apnea. In: Kryger MH Roth T, Dement WC (Eds). Principles and Practice of Sleep Medicine. Philadelphia : W.B. Saunders Company, 1994; 667-77.

20. Al-Alawi A, Mulgrew A, Tench E, Ryan CF. Prevalence, risk factors and impact on day time sleepiness and hypertension of periodic leg movements with arousals in patients with obstructive sleep apnea. J Clin Sleep Med 2006;15:2:281-7.

21. Manconi M, Zavalko I, Bassetti CL, Colamartino E, Pons M, Ferri R. Respiratory-related leg movements and their relationship with periodic leg movements during sleep. Sleep 2014;37:494-504. 